\title{
Entrepreneurship gaps framework model: An early-stage business diagnostic tool
}

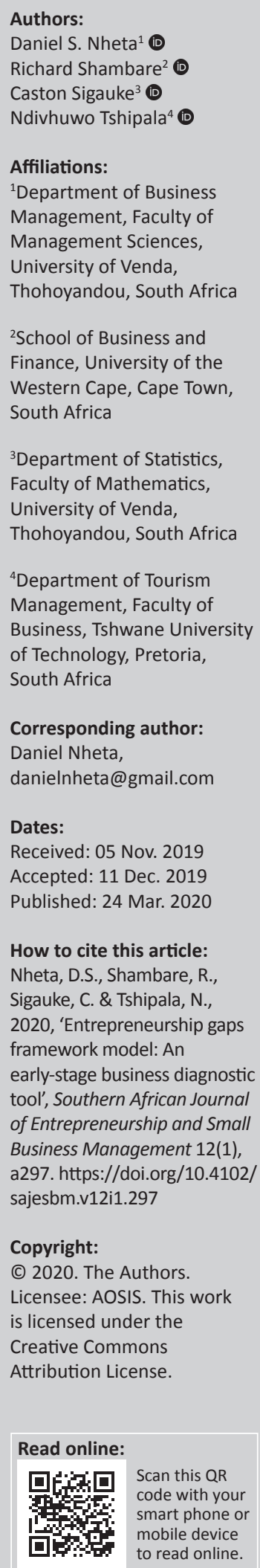

Background: In South Africa, entrepreneurship literature demonstrates that three out of four businesses collapse within 3 years of their inception. A plethora of research effort identifies factors such as the lack of finance and access to markets as the leading causes for the high attrition rates amongst emerging businesses. This study finds the narrative to be limiting and inadequate as it does not address the possible gap between entrepreneurs' expectations and their realities of managing their businesses.

Aim: To present the entrepreneurship gaps framework (EGF), an early-stage business diagnostic tool that seeks to assess entrepreneurs' preparedness.

Setting: This study focused on emerging entrepreneurs operating within the limits of developing economies. The framework can be used by emerging entrepreneurs, capacity development institutions and lenders.

Methods: A descriptive research design supported by a mixed-method research approach was employed. This was coupled by a two-phase data collection procedure which took place within Limpopo province with 215 participants. Explorative data analysis based on discrete choice models was further implemented.

Results: Findings on the EGF illustrated the ability of the framework to act as a more comprehensive diagnostic mechanism that improves early-stage entrepreneurship survival.

Conclusion: Entrepreneurship gaps framework is a decision-making tool that can be used by lenders and capacity development institutions to evaluate the emerging entrepreneur with respect to specific areas of business. This results in the necessary support for improving entrepreneur preparedness being provided to entrepreneurs. Secondly, entrepreneurs are likely to benefit from the EGF, if used as a self-diagnostic tool to measure their business preparedness and experience.

Keywords: entrepreneurship; entrepreneurship gap; entrepreneurship gap framework; expectations; realities.

\section{Introduction}

The existing narratives on early- or formative-stage business failure are misleading, and at best, impoverished. In a multitude of theses, journal articles and case studies, the cliché '3-out-of-4 businesses collapse within three years' is almost always followed by recommendations such as, amongst others: (1) government must improve the access to new markets for Small and Medium Enterprises (SMEs) and (2) banks ought to be more business-friendly (Adonisi \& Van Wyk 2012; Chinomona \& Maziriri 2015; Lekhanya 2016; Luiz \& Martine 2011; Secundo et al. 2017). Whilst this at times is correct, this article argues that this perspective is too limiting and inadequate in providing a more holistic account of early-stage business failure. This article is persuaded to consider entrepreneurship as a trade and as with any trade (e.g. carpentry, music or medicine), a tradesman specialises and consolidates experience in a sub-discipline such as neurosurgery - a highly specialised field of medicine that deals with brain surgery. With the above parallelism of entrepreneurship to neurosurgery in mind, it is argued that despite a neurosurgeon being a 'doctor', not any doctor can perform brain surgery.

From the above discussion, it is postulated that emerging entrepreneurs may experience a discrepancy between their expectations of running a business versus the realities presented by owning and managing a 'real' business. We refer to this discrepancy (the difference between expectations and reality) as the entrepreneurship gap (EG). More formally, EG = expectations realities. Therefore, when expectations are considerably higher than the business realities 
(high EG), the entrepreneur's ability to deal with the inconsistency becomes fundamental. On the other hand, lower EG tends to be associated with businesses with a higher propensity to survive as the entrepreneurs have much fewer issues to deal with. Against this background, the purpose of this research is to construct the entrepreneurship gaps framework (EGF) that will assist in assessing the preparedness of entrepreneurs in the formative stage of business (less than 3 years in existence).

\section{Problem investigated}

The lack of self-assessment tools in the South African context that assess emerging entrepreneurs' level of business preparedness (including expectations) is a challenge that capacity development institutions and financial institutions encounter. The need to determine the level of individual support that emerging entrepreneurs require has not been thoroughly addressed as compared to the need for resources. This creates a need for workable solutions that address the challenge (Al-Lamki et al. 2016; Parliamentary Monitoring Group 2012; Underhill Corporate Solutions 2011).

\section{Research objective}

The objective of this article is to report on the development process of an EGF. This will involve identifying specific gaps within the ambit of literature of which the gaps are professed to be common factors of entrepreneurs' expectations.

\section{Underpinning theories}

The context of the study has two aspects that establish the foundation of EG. A closer look reveals the entrepreneur and the business components. Within the entrepreneurship field, various theories have been effectually used in dissecting and attempting to establish the foundation of EG (see Table 1).

A closer look at the theories given in Table 1 reveals that the discrepancy theory has been applied towards understanding the individual (entrepreneur) in relation to the expectations against achieved standards presented by the business

TABLE 1: Underpinning theories in previous studies.

\begin{tabular}{|c|c|c|}
\hline Author & Study area & Underpinning theory \\
\hline Cooper and Artz (1995) & Determinants of satisfaction & Discrepancy theory \\
\hline Steel and Konig (2006) & Theories of motivation & Expectancy theory \\
\hline $\begin{array}{l}\text { Fitzsimmons and } \\
\text { Douglas (2011) }\end{array}$ & Entrepreneurial intentions & Expectancy theory \\
\hline $\begin{array}{l}\text { Gorgievski, Ascalon and } \\
\text { Stephan (2011) }\end{array}$ & $\begin{array}{l}\text { Small business owners' } \\
\text { success }\end{array}$ & Theory of human values \\
\hline $\begin{array}{l}\text { Renko, Kroeck and } \\
\text { Bullough (2011) }\end{array}$ & Business start-up process & Expectancy theory \\
\hline $\begin{array}{l}\text { Fast, Burris and Bartel } \\
\text { (2014)a }\end{array}$ & Managerial self-efficacy & Discrepancy theory \\
\hline Malebana (2014) & Entrepreneurial intentions & Theory of planned behaviour \\
\hline $\begin{array}{l}\text { Barba-Sanchez and } \\
\text { Atienza-Sahuquilb (2017) }\end{array}$ & Entrepreneurial motivation & Expectancy theory \\
\hline
\end{tabular}

Note: Please see the full reference list of the article, Nheta, D.S., Shambare, R., Sigauke, C. \& Tshipala, N., 2020, 'Entrepreneurship gaps framework model: An early-stage business diagnostic tool', Southern African Journal of Entrepreneurship and Small Business Managemen 12(1), a297. https://doi.org/10.4102/sajesbm.v12i1.297, for more information. component (Cooper \& Artz 1995; Fast et al. 2014). A discrepancy in this matter is a perceived difference of determined standards and the level of accomplishment attained thereof.

Discrepancy theorists articulate that the existence of such a difference may lead to emotive or active reactions, even to an extent of dismissal of set standards. This outcome is derived from various sources, such as social pressure, threshold requirements and personal expectations, amongst others (Locke 1969; Oliver 1981). The discrepancy theory thereby suitably applies to this study as it assists in understanding the discrepancies faced by an entrepreneur in the world of business unequivocally, instituting the conceptual framework of the study.

\section{Conceptual framework}

Dichotomising the postulated EG foundation and focusing on the entrepreneur component, Figure 1 was developed to comprehend formative stage business failure by analysing individual business expectations against entrepreneurship business realities. The elements at the left of the demarcation line (in Figure 1) represent the cliché of personal expectations faced by entrepreneurs in the formative stage of business. These expectations vary from personal to business-related expectations. Contrary to the expectations, at the right side of the demarcation line are the realities of operating a business. For instance, an emerging entrepreneur may expect to have less time at work because they oversee it as opposed to an employee who works for 8:00-17:00. However, the reality of operating the business may result in more time being required at work. The difference between these two levels creates an entrepreneurial gap. Figure 1 thus provides an illustration of the components of the conceptual framework.

Most of the previous studies have focused on issues such as the gender gap in entrepreneurship and meandered its way into the family gap (FG) with respect to women entrepreneurs. But at this point, there is still more to be done concerning the gap illustrated in Figure 1 with respect to a holistic entrepreneurship understanding (Djankov, Nikolova \& Zilinsky 2016; Haugh \&

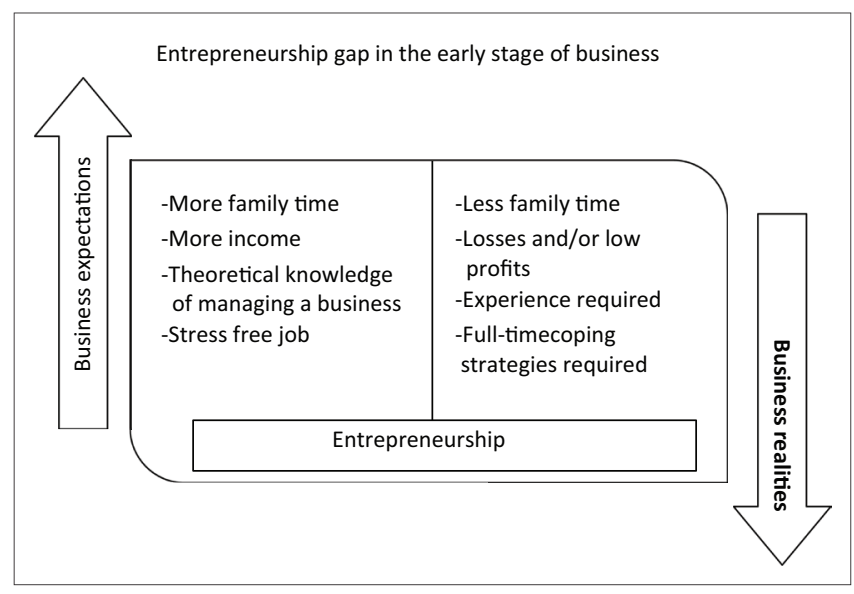

FIGURE 1: Entrepreneurship gap in the early stage. 
TABLE 2: Identification of gaps.

\begin{tabular}{lll}
\hline Gap & Author & Study area \\
\hline Family gap & - McGowan et al. (2012) & - Management of business \\
& - Ramadani (2015) & - Women entrepreneurship \\
Income gap & - Metzger (2008) & - Entrepreneurial success \\
& - Haugh and Talwar (2016) & - Firm closure \\
& - Social entrepreneurship \\
Skills gap & - Cooper (2017) & - Financial optimism \\
& - Khelil (2016) & - Entrepreneurial success \\
Stress gap & - Delsh et al. (2016) & - Entrepreneurial failure \\
& & - Entrepreneurship \\
& & - Economics, Psychology, \\
\hline
\end{tabular}

Note: Please see the full reference list of the article, Nheta, D.S., Shambare, R., Sigauke, C. \& Tshipala, N., 2020, 'Entrepreneurship gaps framework model: An early-stage busines diagnostic tool', Southern African Journal of Entrepreneurship and Small Business Management 12(1), a297. https://doi.org/10.4102/sajesbm.v12i1.297, for more information.

Talwar 2016; Ismail et al. 2016; Ramadani 2015; Raven \& Le 2015; Welsh, Memili \& Kaciak 2016).

To perambulate the conceptual framework of the EGs, this study adopted a parameter that has four specific EGs of interest, which include FG, income gap (IG), skills gap (SG) and stress gap (StG), with the gaps development derived from various fields of study (see Table 2). The challenges that entrepreneurs encounter stem from these mentioned gaps. The entrepreneur's level of preparedness is put to the test. It is upon this platform where the entrepreneur must put into practice one's abilities to confront the challenge arising from the gap based on the extent to which the challenges were expected. Failure to implement necessary adjustments at this point is presumed to widen the gap, infusing more operating challenges and resulting in the collapse of the business if unsuccessfully managed.

As it is illuminated in this article (see Figure 1), EG is created when a difference exists between individual expectations and actualities of operating a business. At this point, if an individual intends to launch a business venture, one might have expectations such as freedom from commands, easy work, sustained income and even job satisfaction to be the reward of being an entrepreneur (McGowan et al. 2012; Ucbasaran et al. 2013).

Some of these expectations, amongst others, are comprehended to drive the individual into entrepreneurship in the anticipation that the expectations will materialise. However, there are business realities.

The business realities are experienced by the entrepreneur when operating a business, for example, health problems arising from overworking, financial risk and even bankruptcy, which are part and parcel of entrepreneurship (Djankov et al. 2016; Haugh \& Talwar 2016). These have an antagonistic effect on the entrepreneur's survival in entrepreneurship at the same time, and would possibly withhold the materialisation of the individual's expectations.

In devastating situations where expectations fail to materialise, it requires the individual to implement certain remedies to combat any challenges arising from withheld or unmet expectations. Inherently, the entrepreneur is susceptible to personal 'failure' in which if one fails to initiate necessary adjustments that would resuscitate the entrepreneur - that is, if his or her expectations do not materialise - it would lead to business failure (Dias \& Teixeira 2017; Jenkins \& McKelvie 2016; Ucbasaran et al. 2013). But, nonetheless, withheld expectations do not necessarily mean that the business has failed; it simply means something has gone wrong or no longer works and hence corrective action is required (Arasti 2011; Fatoki 2014a, 2014b; Mutoko \& Kapunda 2017; Pretorius \& Le Roux 2011).

Deliberating from the aforementioned discussion, this background could be one of the reasons why a high attrition rate of emerging business ventures exists as individuals give up soon yet there could be remedial ways to resuscitate the business before it collapses. One is, therefore, inclined to accept that the high number of early-stage business failures in South Africa, amongst other reasons, is also caused by the absence of a diagnostic tool that would reduce such a predicament. Entrepreneurship gap analysis would thereby provide a platform to understand the possibility of whether an entrepreneur is likely to succeed in operating a business or fail to do so. Such an attempt can best be achieved by using suitable research methods based on the conceptual framework.

\section{Research methodology}

To attain the objective of this article, the study was conducted in Limpopo province, with entrepreneurship academics and entrepreneurs composing the population. A descriptive research design supported by a mixed-method approach was employed. This was coupled with a twophase data collection procedure (Sibindi \& Aren 2015). Phase 1 involved in-depth interviews in order to extract expectations and realities pertaining to entrepreneurship. These realities and expectations were then used to develop a questionnaire. These themes were validated by key experts in the field of entrepreneurship whilst supported by the literature. Phase 2 then used a structured selfcompleting questionnaire with questions derived from Phase 1 themes.

The instrument was subjected to factor analysis and Cronbach's alpha test for reliability, with a pilot study being conducted to retest the instrument for validity purposes. The purpose of Phase 2 was to extract quantitative data for modelling. Fifteen respondents for Phase 1 were purposively approached (Ilker, Sulaiman \& Rukayya 2015). The respondents were operating a small business, had been in business for at least 3 years and were of any gender despite the type of business. This was done to ensure that a broader spectrum of what entrepreneurs encounter in their career is achieved. Hence, it establishes a platform for future researchers to narrow the purpose to specific areas of interest.

For Phase 2, a minimum of 200 respondents were randomly approached. The difference from Phase 1 is that entrepreneurs selected for Phase 2 were operating a business still in the 
early stage (not more than 3 years). For both phases, it was ensured that informed respondents freely participated and that they had the right to withdraw from the study at any moment. Ethical research principles governed the behaviour of the researchers as the survey was conducted. The series of events was then rounded up by explorative data analysis grounded on discrete choice models (DCMs).

\section{Modelling framework}

The development of a pragmatic model required a modelling framework that set the course of events concerning the variables of interest. To materialise this concept, DCMs were applied. A DCM is used in explaining, describing and predicting sets (choices) of two or more discrete options (Sarrias 2016). The general DCM is given in Equation 1:

$y_{i t}=x_{i t}^{T} \beta_{i}+\varepsilon_{i t}$

[Eqn 1]

where $Y_{\mathrm{it}}$ is the process for individual $i=1, \ldots, n$ in period $t=1, \ldots T, x_{\text {it }}$ is a vector of independent variables (covariates) and $\varepsilon_{\mathrm{it}}$ is an error term. The general formulation of Equation 1 falls under one of the following binary, ordered and Poisson models given in Equation 2 (Sarrias 2016):

$$
f\left(y_{i t} \mid x_{i t}, \beta_{i}\right)=\left\{\begin{array}{c}
{\left[F\left(x_{i t}^{T} \beta_{i}\right)\right]^{y_{i t}}\left[1-F\left(x_{i t}^{T} \beta_{i}\right)\right]^{1-y_{i t}}} \\
\prod_{j=1}^{J}\left[F\left(k_{j}-x_{i t}^{T} \beta_{i}\right)-F\left(k_{j-1}-x_{i t}^{T} \beta_{i}\right)\right]^{y_{i j}} \\
\frac{1}{y_{i t} !} \exp \left[-\exp \left(x_{i t}^{T} \beta_{i}\right)\right] \exp \left(x_{i t}^{T} \beta_{i}\right)^{y_{i t}}
\end{array}\right.
$$

[Eqn 2]

From Equation 2, for the binary model, $F($.$) denotes the$ distribution function of the error term, for which $F(\varepsilon)=\Lambda(\varepsilon)$ represents the logit model (logistic regression model). For the ordered model, $k_{\mathrm{j}}$ denotes a threshold of choice. $j=1, \ldots, J-1$.

For this study, let $E G=$ expectations - realities, then if $E G>\tau$, where $\tau$ is a predetermined threshold, then this indicates a high risk entrepreneur based on the entrepreneurial gap. Let $P\left(E G_{i t}=1 \mid x_{i t}\right)$ be the probability of a high risk of business failure, then:

$$
P\left(E G_{i t}=1 \mid x_{i t}\right)=\frac{1}{1+e^{-E G_{i t}}}
$$

where:

$$
E G_{i t}=c+x_{i t}^{T} \beta_{i}+\varepsilon_{i t}, i=1, \ldots, n ; t=1, \ldots, T
$$

with:

$$
E G_{i t}=\left\{\begin{array}{c}
1, \text { if } E G_{i t} \geq \tau \\
0, \text { otherwise }
\end{array}\right.
$$

where $E G_{i t}$ takes value 1 if EG exceeds a predetermined threshold $\tau, x_{i t}$ denotes the set of predictor variables (i.e. $f F G, I G, S G$, and $S t G$ ). Therefore:
$E G_{i t}=c+\beta_{1} F G_{i t}+\beta_{2} I G_{i t}+\beta_{3} S G_{i t}+\beta_{4} S t G_{i t}+\varepsilon_{i t}$

[Eqn 6]

The parameters of Equation 6 will be estimated using the maximum likelihood (ML) method. The log-likelihood function, $L\left(\beta \mid x_{\mathrm{it})}\right.$ is given in Equation 7:

$$
\begin{array}{r}
\ln L\left(\beta \mid x_{i t}\right)=\sum_{i=1}^{n}\left[\left(1-E G_{i t}\right) \ln P\left(E G_{i t}=0 \mid x_{i t}, \beta\right)\right. \\
+E G_{i t} \ln P\left(E G_{i t}=1 \mid x_{i t}, \beta\right)
\end{array}
$$

\section{Ethical consideration}

This article followed all ethical standards for research with direct contact with human or animal subjects.

\section{Results}

The results presented in this section are derived from Phase 2 data collection in line with testing the model. Respondents who met the criteria of operating a business for less than 3 years of existence were randomly selected. A total of 215 respondents managed to provide meaningful data which were advanced for further analysis. The modelling and analysis were done using the open-source software $R$ version 3.6.0, which is available on the R CRAN (https:/ / cran.r-project.org/).

Figure 2 illustrates the normal distribution of EG on data of 215 observations with four variables. There were a total of 215 respondents. This was split into two sets: a training set with $n_{1}=200$ respondents and a validation set of $n_{2}=15$ respondents. Elastic net regression was used to prevent overfitting through shrinkage methods of Ridge and Lasso, resultantly providing meaningful data for predictions (Hastie, Tibshirani \& Wainwright 2015).

For a start, if $E G>0$, it implies likely challenges in running the business, which may stir business failure if EG has a large positive value. This article initially set the threshold $(\tau)$ to help in determining a binary variable for EG for which if $E G>\tau$, this would signal serious challenges the entrepreneur is likely to face. This threshold, $\tau$, was determined as the average of the positive EGs from the training set and was found to be $t=0.405996$.

With EG plots known, the ability of the entrepreneur to adjust accordingly when facing business challenges could be determined. As in Figure 3, respondents above the threshold level face a dilemma of surviving the early stage of business as compared to respondents plotted below the threshold. A cross-validation test using Lambda was conducted, which validated the model and its ability to predict the likelihood of an entrepreneur's level of preparedness.

\section{Discussion}

To illustrate the concept expressed by Equation 6, Figure 4 presents an example of EGF. As presented in the figure, EG is subjected to entrepreneurs' expectations. Within the 


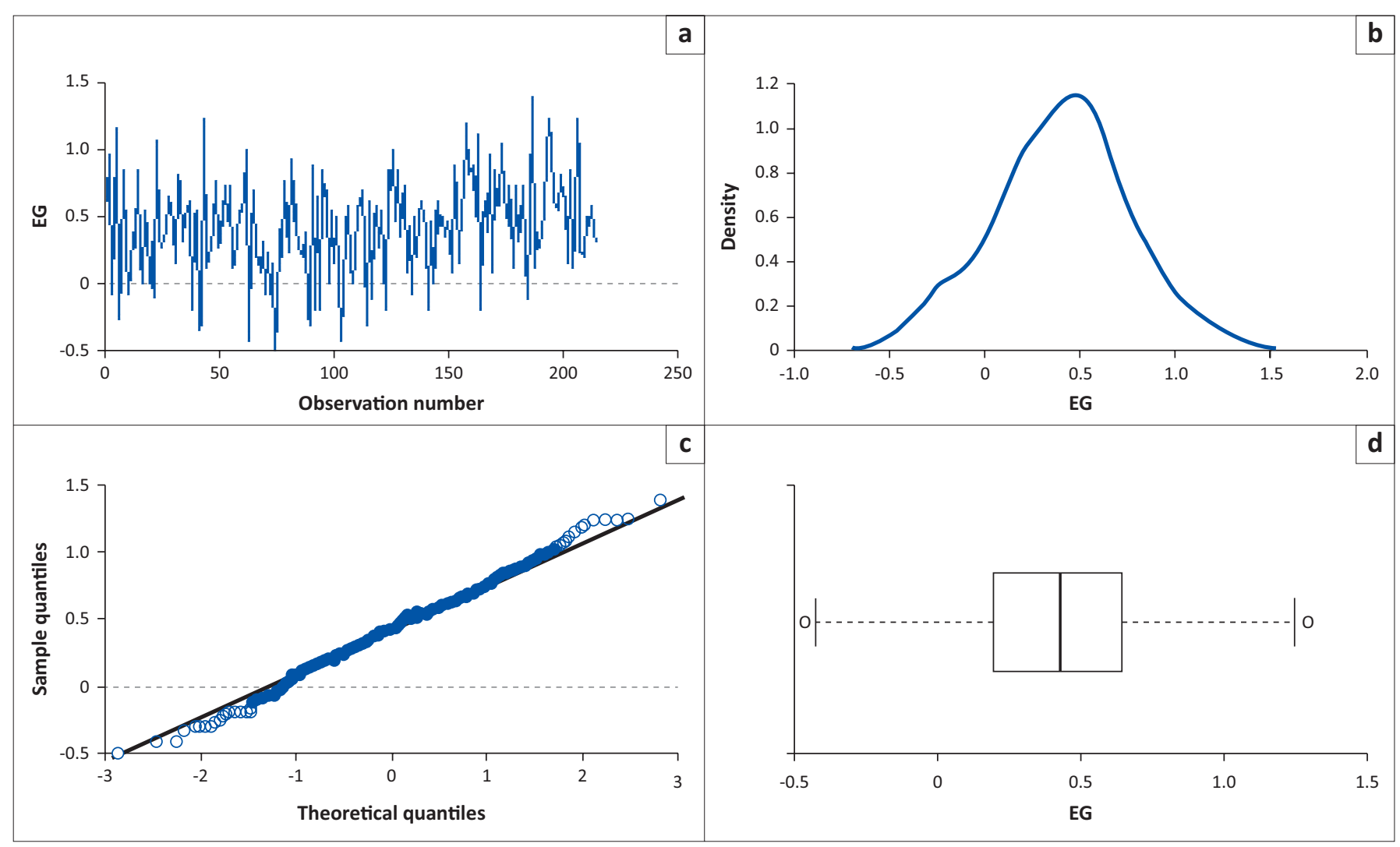

EG, Entrepreneurship gap.

FIGURE 2: Plot of entrepreneurship gap based on a sample of 215 respondents: (a) plot of entrepreneurship gap; (b) density of entrepreneurship gap; (c) normal QQ plot of entrepreneurship gap; (d) boxplot of entrepreneurship gap.

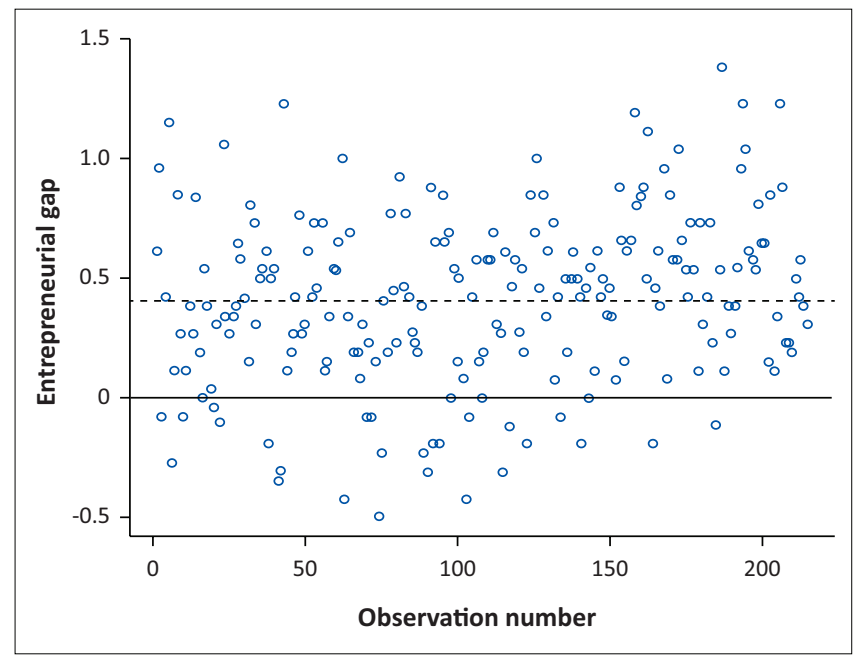

Note: The horizontal dotted line denotes the threshold $(t=0.405996)$.

FIGURE 3: Plot of entrepreneurship gap.

context of this article, these expectations are subject to four major variables - FG, IG, SG and StG - which are presented as factors determining the position of EG and thereby providing a starting point for understanding entrepreneurship failure. The illustration in Figure 4 shows the existence of two zones. Zone 1 shows the area of a high personal risk which is likely to induce business failure, whilst Zone 2 demarcates the area of a low personal risk with respect to inducing business failure; however, this is dependent on the position of EG.
In Zone 1, an entrepreneur who is above the EG line - that is, has higher EG levels - is postulated to have misaligned business expectations to business realities. Equally, the individual experiences more pressure in terms of adjusting to entrepreneurship as one would not have expected such necessary changes. This is attributed to the necessity of effectively adjusting to business realities and the subsequent challenges arising thereof because of different factors contributing to the entrepreneurial gaps which are unaccounted for during the business adjustment process. In contrast, an entrepreneur below EG line (Zone 2) is less likely to be affected.

Entrepreneurs with lower levels of EG tend to have businesses with a higher propensity to survive. As postulated, the entrepreneurs expect and account for possible business adjustments in a manageable condition because business expectations and realities are more aligned.

The high attrition rate of emerging businesses in South Africa signifies the need to develop workable means or methods that could be used to decrease the rate of early-stage business failure and, therefore, to improve economic growth. The proposed framework provides a diagnostic tool as a possible solution for the entrepreneur and simultaneously acts as a decision tool for Capacity Development Institutions (CDIs) which is something that has been indirectly requested by Underhill Corporate Solutions (2011), Ruiz, Soriano and Coduras (2015) and Olugbola (2017). When the EG position 


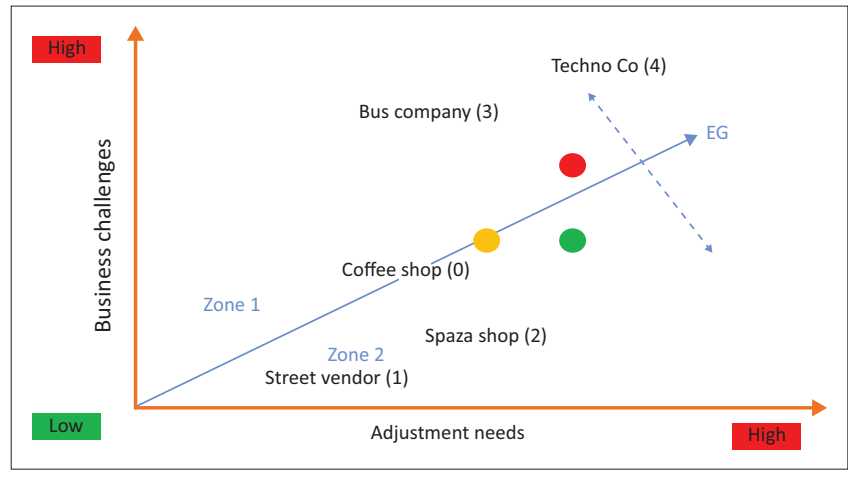

FIGURE 4: Entrepreneurship gap framework.

has been identified, the entrepreneurs should re-evaluate their expectations in line with the propensity of the business to deliver those expectations. This would, however, require improving the individual's preparedness wherein CDIs could stimulate such improvements through effective monitoring and evaluation.

A closer look at CDIs making use of the framework reveals how managers can improve their services. With limited resources available, CDI managers in charge of allocating funds are restricted to make decisions based on the business component alone. At the emergence of EGF, managers can now have a comprehensive understanding of the entrepreneur together with the business component. Progressively, a holistic understanding of the client seeking funds will thus be achieved by providing reasonable information that every manager in charge of funds would greatly embrace. At best, managers can therefore predict the entrepreneur's likelihood of success or not, thereby creating a platform for sound decisions to be made.

Irrespective of managerial position, entrepreneurs making use of the EGF should bear in mind the constant need to stay at par with business realities, of which EGF is a tool that could be used in such cases.

\section{Conclusion}

From the findings of this study, it can be concluded that the EGF will act as a more comprehensive diagnostic mechanism to improve early-stage entrepreneurship survival. The framework addresses the need for an entrepreneur to adjust successfully to business realities. At ease, entrepreneurs will be able to assess their ability to effect necessary changes towards establishing and operating a successful venture based on the results of the framework. This assessment, in addition, should lead to the identification of problem areas and conceive the implementation of remedies that advances the chances of entrepreneurship survival. As the framework consists of the main factors affecting early-stage entrepreneurship as supported by the literature - the four gaps indicated in Table 2 and Equation 6 individuals will be assessed against these factors. The results thereof will display the entrepreneurial gap of the respective individual. As a start, relevant support with regard to advising and mentoring will be provided, improving the chances of the emerging entrepreneur to adjust to business realities.
Simultaneously, the CDIs can re-evaluate their strategies towards entrepreneurship development, resulting in them providing the vital support resources to categories of entrepreneurs. The collaborative efforts of the entrepreneur and the support structures would, in turn, be assisted by an EG diagnostic tool that would enhance entrepreneurship survival in emerging economies.

This process should assist in developing strategic avenues that emerging businesses could consider to effectively manage initial challenges associated with high EG levels and business adjustment process. With such outputs from this article, policymakers, emerging entrepreneurs and interested stakeholders would have a more comprehensive and informed platform to tackle early-stage business failure, which should, eventually, lead to improved survival ratings of emerging businesses in South Africa.

\section{Acknowledgements}

The authors express their gratitude to the University of Venda for funding this research project. In addition, we appreciate the collaborations that emerged as a result of this project. Lastly to our friends, family and colleagues, we thank you for your support.

\section{Competing interests}

The authors have declared that no competing interest exists.

\section{Authors' contributions}

All authors contributed equally to this work.

\section{Funding information}

The University of Venda Research Project Committee funded the project.

\section{Data availability statement}

Data are available upon request.

\section{Disclaimer}

The views and opinions expressed in this article are those of the authors and do not necessarily reflect the official policy or position of any affiliated agency of the authors.

\section{References}

Adonisi, M. \& Van Wyk, R., 2012, 'The influence of market orientation, flexibility and job satisfaction on corporate entrepreneurship', International Business \& Economics Research Journal 11(5), 477-486. https://doi.org/10.19030/iber.v11i5.6966

Al-Lamki, R., Al-Sumri, M., Al-Ismaili, S. \& Al-Busaidi, K.A., 2016, 'An expert system to determine the probability of success and readiness in entrepreneurship', International Journal of Computing \& Information Sciences 12(2), 189-196. https://doi.org/10.21700/ijcis.2016.122

Arasti, Z., 2011, 'An empirical study on the causes of business failure in Iranian context', African Journal of Business Management 5(17), 7488-7498. https://doi. org/10.5897/AJBM11.402

Barba-Sanchez, V. \& Atienza-Sahuquilb, C., 2017, 'Entrepreneurial motivation and selfemployment: Evidence from expectancy theory', International Entrepreneurship Management Journal 13, 1097-1115. https://doi.org/10.1007/s11365-017-0441-z 
Chinomona, E. \& Maziriri, E.T., 2015, 'Women in action: Challenges facing women entrepreneurs in the Gauteng province of South Africa', International Business \& Economics Research Journal 14(6), 835-850. https://doi.org/10.19030/iber. $\&$ Economics
$\mathrm{v} 14 \mathrm{i} 6.9487$

Cooper, A.C. \& Artz, K.W., 1995, 'Determinants of satisfaction for entrepreneurship', Journal of Business Venturing 10(6), 439-457. https://doi.org/10.1016/08839026(95)00083-K

Dawson, C., 2017, 'Financial optimism and entrepreneurial satisfaction', Strategic Entrepreneurship Journal 11(2), 171-194. https://doi.org/10.1002/sej.1244

Dias, A. \& Teixeira, A.C.A., 2017, 'The anatomy of business failure: A qualitative account of its implications for future business success', European Journal of Management and Business Economics 26(1), 2-20. https://doi.org/10.1108/ EJMBE-07-2017-001

Djankov, S., Nikolova, E. \& Zilinsky, J., 2016, 'The happiness gap in Eastern Europe', Journal of Comparative Economic 44(1), 108-124. https://doi.org/10.1016/j. jce.2015.10.006

Fast, N.J., Burris, E.R. \& Bartel, C.A., 2014, 'Managing to stay in the dark: Managerial self-efficacy, ego defensiveness, and the aversion to employee voice', Academy of Management Journal 57(4), 1013-1034. https://doi.org/10.5465/amj.2012.0393

Fatoki, O., 2014a, 'The entrepreneurial intention of undergraduate students in South Africa: The influences of entrepreneurship education and previous work experience', Mediterranean Journal of Social Sciences 5(7), 294-299. https://doi. org/10.5901/mjss.2014.v5n7p294

Fatoki, O., 2014b, 'The causes of the failure of new small and medium enterprises in South Africa', Mediterranean Journal of Social Sciences 5(20), 922-927. https:// doi.org/10.5901/mjss.2014.v5n20p922

Fitzsimmons, R.J. \& Douglas, E.J., 2011, 'Interaction between feasibility and desirability in the formation of entrepreneurial intentions', Journal of Business Venturing 26(4), 431-440. https://doi.org/10.1016/j.jbusvent.2010.01.001

Gorgievski, M.J., Ascalon, M.E. \& Stephan, U., 2011, 'Small business owners' success criteria, a values approach to personal differences', Journal of Small Business

Hastie, T., Tibshirani, R. \& Wainwright, M., 2015, Statistical learning with sparsity: The Lasso and generalization, CRC Press, London.

Haugh, H.M. \& Talwar, A., 2016, 'Linking social entrepreneurship and social change: The mediating role of empowerment', Journal of Business Ethics 133(4), 643-658. https://doi.org/10.1007/s10551-014-2449-4

Ilker, E., Sulaiman, A.M. \& Rukayya, S.A., 2015, 'Comparison of convenience sampling and purposive sampling', American Journal of Theoretical and Applied Statistics 5(1), 1-4. https://doi.org/10.11648/j.ajtas.20160501.11

Ismail, I., Husin, N., Rahim, N.A., Kamal, M.H.M. \& Mat, R.C., 2016, 'Entrepreneurial success among single mothers: The role of motivation and passion', Procedia
Economics and Finance 37(16), 121-128. https://doi.org/10.1016/S2212Economics and
5671(16)30102-2

Jenkins, A. \& McKelvie, A., 2016, 'What is entrepreneurial failure? Implications for future research', International Small Business Journal, 34(2) 176-188. https://doi. org/10.1177/0266242615574011

Khelil, N., 2016, 'The many faces of entrepreneurial failure: Insights from an empirical taxonomy', Journal of Business Venturing 31(1), 72-94. https://doi.org/10.1016/j. jbusvent.2015.08.001

Lekhanya, L.M., 2016, 'Business characteristics of small and medium enterprises in rural areas: A case study on southern region of KwaZulu-Natal province of South Africa', Problems and Perspectives in Management 14(3), 108-114. https://doi. org/10.21511/ppm.14(3).2016.11

Locke, E., 1969, 'What is job satisfaction?', Organizational Behavior \& Human Performance 4(4), 309-336. https://doi.org/10.1016/0030-5073(69)90013-0

Luiz, J. \&. Martine, M., 2011, 'Entrepreneurship in an emerging and culturally diverse economy: A South African survey of perceptions', South African Journal of Economics and Management 14(1), 47-65. https://doi.org/10.4102/sajems.v14i1.30

Malebana, J., 2014, 'Entrepeneurial intentions of South African rural university students: A test of the theory of planned behaviour', Journal of Economics and Behavioural Studies 6(2), 130-143.
McGowan, P., Redeker, C.L., Cooper, S.Y. \& Greenan, K., 2012, 'Female entrepreneurship and the management of business and domestic roles: Motivations, expectations and realities', Entrepreneurship \& Regional Development 24(1-2), 53-72. https:// and realities', Entrepreneurship \& Regiona
doi.org/10.1080/08985626.2012.637351

Metzger, G., 2008, 'Firm closure, financial losses and the consequences for an entrepreneurial restart', ZEW Discussion Papers, pp. 8-094, Zentrum für Europäische Wirtschaftsforschung (ZEW), Mannheim.

Mutoko, W.R. \& Kapunda, S.M., 2017, 'Factors influencing small, medium and microsized enterprises' borrowing from banks: The case of the Botswana manufacturing sector', Acta Commercii: Independent Research Journal in the Management Sciences 17(1), 1-9. https://doi.org/10.4102/ac.v17i1.426

Oliver, R.L., 1981, 'Measurement and evaluation of satisfaction processes in retail settings', Journal of Retailing 57(3), 25-48.

Olugbola, A.S., 2017, 'Exploring entrepreneurial readiness of youth and startup success components: Entrepreneurship training as a moderator', Journal of Innovation \& Knowledge 2(3), 155-171. https://doi.org/10.1016/j.jik.2016. 12.004

Parliamentary Monitoring Group, 2012, Access to funding by small enterprises: Commercial banks and development finance institutions briefing, viewed 25 May 2018, from https://pmg.org.za/committee-meeting/14497/.

Pretorius, M. \& Le Roux, I., 2011, 'Successive failure, repeat entrepreneurship and no learning: A case study', SA Journal of Human Resource Management/SA 9(1), 1-13. https://doi.org/10.4102/sajhrm.v9i1.236

Ramadani, V., 2015, 'The woman entrepreneur in Albania: An exploratory study on motivation, problems and success factors', Journal of Balkan and Near Eastern Studies 17(2), 204-221. https://doi.org/10.1080/19448953.2014.997488

Raven, P. \& Le, Q.V., 2015, 'Teaching business skills to women: Impact of business training on women's microenterprise owners in Vietnam', International Journal of Entrepreneurial Behavior \& Research 21(4), 622-641. https://doi.org/10.1108/ IJEBR-06-2014-0099

Renko, M., Kroeck, G. \& Bullough, A., 2011, 'Expectancy theory and nascent entrepreneurship', Small Business Economics 39(3), 667-684. https://doi. org/10.1007/s11187-011-9354-3

Ruiz, J., Soriano, D.R. \& Coduras, A., 2015, 'Challenges in measuring readiness for entrepreneurship', Management Decision 54(5), 1022-1046. https://doi. org/10.1108/MD-07-2014-0493

Sarrias, M., 2016, 'Discrete choices with random parameters in R: The Rchoice package', Journal of Statistical Software 74(10), 1-31. https://doi.org/10.18637/ package', Journ

Secundo, G., Vecchio, P.D., Schiuma, G. \& Passiante, G., 2017, 'Activating entrepreneurial learning processes for transforming university students' idea into entrepreneurial practices', International Journal of Entrepreneurial Behavior \& entrepreneurial practices', International Journal of Entrepreneurial Beha
Research 23(3), 465-485. https://doi.org/10.1108/IJEBR-12-2015-0315

Sibindi, A.B. \& Aren, A.O., 2015, 'Is good corporate governance practice the panacea for small-to-medium businesses operating in the South African retail sector?', Corporate Ownership \& Control 12(2), 579-589. https://doi.org/10.22495/ corporate Ow $12 \mathrm{i} 2 \mathrm{c} 6 \mathrm{p} 1$

Steel, P. \& Konig, C.J., 2006, 'Integrating theories of motivation', Academy of Management Review 31(4), 889-913. https://doi.org/10.5465/amr.2006. 22527462

Ucbasaran, D., Shepherd, D.A., Locket, A. \& Lyon, J.S., 2013, 'Life after business failure: The process and consequences of business failure for entrepreneurs', Journal of Management 39(1), 163-202. https://doi.org/10.1177/0149206312457823

Underhill Corporate Solutions (UCS), 2011, Literature review on small and medium enterprises' access to credit and support in South Africa, viewed 25 May 2018, from https://www.ncr.org.za/pdfs/Literature $\% 20$ Review $\% 20$ on $\% 20$ SME $\% 20$ Access $\% 20$ to $\% 20$ Credit $\% 20$ in $\% 20$ South $\% 20$ Africa_Final\%20Report_NCR Dec\%202011.pdf.

Welsh, D.H.B., Memili, E. \& Kaciak, E., 2016, 'An empirical analysis of the impact of family moral support on Turkish women entrepreneurs', Journal of Innovation \& Knowledge 1(1), 3-12. https://doi.org/10.1016/j.jik.2016.01.012 